\title{
PREPARAÇÃO DOS ALUNOS DE ADMINISTRAÇÃO PARTICIPANTES DE EMPRESAS JUNIORES PARA O MERCADO DE TRABALHO
}

Recebido em 17.07.2014. Aprovado em 10.10.2014 Avaliado pelo sistema double blind review

\author{
Francisco Cavalcanti Reis \\ franciscoreis85@hotmail.com
}

\begin{abstract}
Resumo
O presente artigo busca identificar como os estudantes do curso de Administração que atuaram em Empresas Juniores percebem as experiências e vivências neste tipo de organização como fatores de formação e qualificação profissional, preparando-os para a inserção em um cenário marcado pelo desemprego e alto nível de competitividade. Para isso, utilizou-se uma metodologia quantitativa descritiva, com a aplicação de um questionário estruturado para 103 estudantes de Administração que participaram de uma Empresa Junior durante a graduação. Por meio da análise dos resultados, embasada no referencial teórico elaborado, foi possível constatar que a Empresa Junior aparece como alternativa eficaz para suprir as carências do ensino identificadas nas universidades, as quais apesar de terem sido consideradas importantes para a formação e qualificação profissional, apresentam deficiências quanto ao ensino prático e com divergências entre os setores de atuação para os quais elas preparam seus empresários juniores e os setores onde eles desejam exercer sua profissão. Avaliou-se que por meio das vivências e experiências adquiridas na Empresa Junior, é oportunizado ao aluno o desenvolvimento de competências e habilidades desejáveis para um Administrador que não estariam contempladas no ensino oferecido nas salas de aula da graduação, além de possibilitar 0 delineamento de um plano de carreia inicial.
\end{abstract}

PALAVRAS-CHAVE: Empresa Junior. Qualificação profissional. Administração.

\begin{abstract}
The present article seeks to identify how students of Business Administration that participated or are still currently active in Junior Companies perceive their role in these organizations as a contributing factor to their professional growth and qualification, preparing them to enter a scenario characterized by unemployment and high levels of competitiveness. To this end, the quantitative descriptive methodology was used, applying a structured questionnaire to 103 students of Business Administration whom participated in a Junior Company. Through an analysis based on the bibliography consulted, the results showed that Junior Companies are an efficient alternative capable of complementing what universities lack in the fields of study presented to their students, as even though universities were considered important in the process of professional growth and qualification, they do not have enough emphasis on practical teachings and demonstrated to be preparing their students for different career paths than those they intend to follow. It was also found that the experience of participating in a Junior Company allows students the development of competencies and skills that are desirable to an Administrator but are not present in traditional classroom teachings, while also enabling them to better outline an initial career path.
\end{abstract}

KEY WORDS: Junior Companies. Professional qualification. Business Administration. 
Introdução

As empresas têm buscado pessoas capacitadas profissionalmente e elevado os requisitos nos processos seletivos tanto para cargos operacionais quanto estratégicos. Segundo Ramos e Ferreira (2004), grandes corporações estão realizando reestruturações e downsizing, adaptando suas estruturas hierárquicas para modelos mais enxutos e assim reduzindo o número de posições disponíveis. Com isso, o estudante que aspira um dia obter emprego em alguma organização renomada tenta estar um passo a frente de seus concorrentes, adquirindo conhecimento sobre diferentes idiomas, programas e sistemas de informática, vivenciando experiências acadêmicas internacionais e ser possuidor de uma enorme lista de qualidades referentes à sua personalidade e disposição para trabalho no ambiente corporativo.

Além disso, a profissão de administrador ainda é pouco regulamentada, por vezes sendo vista no mercado como uma atividade que não exige necessariamente formação superior no curso de Administração, o que acaba fazendo com que os egressos do curso precisem competir no mercado com egressos dos cursos de engenharia, economia, contábeis e até psicologia em algumas áreas de atuação na empresa. Também merece destaque a proliferação de cursos superiores de Administração nos últimos anos que surgiram sem controle de qualidade, ajudando a inflar o mercado com profissionais da área, sendo o curso superior com mais alunos matriculados segundo Censo da Educação Superior (2012). Com isso, é de interesse das instituições de ensino mais renomadas, capacitarem tecnicamente seus alunos e auxiliá-los no desenvolvimento de atitudes comportamentais que os possibilitem executar 0 ato de administrar de maneira mais eficiente e eficaz que as demais faculdades. Também é importante salientar que o alinhamento entre percepção dos alunos e o objetivo de posicionamento da instituição de ensino é fundamental para que ela obtenha sucesso.

Estudos recentes (COHEN, 2007; EPIHANE; JUGNOT, 2011; MAZARI, MEYER, ROUAUD, RYK; WINNICKI, 2011; RECOTILLET, ROUAUD, RYK, 2011) apontam para uma mudança no método de inserção no mercado de trabalho, antes visto como uma trajetória sequencial composta por escola, universidade e enfim trabalho, agora passa a envolver trajetórias mais distintas onde jovens buscam a inserção por meio de dispositivos públicos, outros por meio de relações familiares ou de vizinhança ou tentam permanecer o maior tempo possível nos estudos, tentando se qualificar para obter uma oportunidade de trabalho estável (ROCHA DE OLIVEIRA, 2012).

Segundo Mainardes (2009), o processo de seleção de empresas está se modificando para atrair talentos que tenham um perfil compatível com a filosofia da empresa e não mais apenas mantendo foco na identificação do candidato com as atividades atribuídas à posição ofertada. Com isso, as Empresas Juniores se apresentam como uma atraente opção para estudantes desenvolverem competências comportamentais por meio da experiência prática logo no início do curso, atuando em diferentes áreas de consultoria como $\mathrm{RH}$, marketing, finanças e planejamento de negócios.

Assim, torna-se interessante avaliar como os participantes de Empresas Juniores (EJ) da Administração estão se preparando para obter um diferencial competitivo para o momento que decidirem iniciar sua vida profissional, que caminhos eles estão seguindo para obter um emprego e iniciar uma carreira e quais ações eles têm planejado para os próximos anos.

\section{Inserção no mercado de trabalho}

O conceito de inserção profissional começa a ser utilizado na França na década de 1970 e o termo começa a aparecer na década seguinte em estudos sobre as dificuldades crescentes de jovens para ingressarem no mercado após concluírem a formação (ROCHA DE OLIVEIRA, 2012).

Cordeiro (2002) ressalta que a inserção profissional vai além da simples aquisição de um posto de trabalho e envolve os processos de pós-inserção que estariam relacionados com as práticas de gestão de mão-de-obra das empresas. Ele categoriza esta etapa da inserção profissional como qualificante e não-qualificante, sendo 
a primeira caracterizada pela busca da empresa em desenvolver as competências individuais e coletivas de seus trabalhadores com políticas de proteção ao trabalhador, condições de trabalho adequadas, contratos estáveis, sistema organizado para progressão de carreira, etc. enquanto a segunda caracteriza-se pela desvalorização do trabalhador por meio de contratos precários, falta de políticas para o desenvolvimento dentro da empresa, baixos salários, etc.

A inserção profissional passa a ser compreendida como um processo de maior complexidade e envolve diversos elementos que influenciam a sua trajetória, possibilitando uma análise das condições de origem do indivíduo, a situação em determinado momento e como ela pode se configurar futuramente dadas as condições atuais.

Dubar (2001 apud ROCHAD DE OLIVEIRA, 2012) identifica diferentes "mundos da inserção" reunindo pessoas que compartilham as mesmas referências, concepções do trabalho, níveis de formação, experiências e estratégias mais ou menos bem coordenadas. Ele menciona os "mundos" da aprendizagem, das pequenas e médias empresas, dos órgãos públicos, dos estágios, grandes empresas, voluntariado entre outros. Cada um desses "mundos" possuindo características diferenciadas e dando origem a um mercado de trabalho com regras específicas que por sua vez originariam diferentes modos de inserção profissional.

O processo de inserção não pode ser compreendido como um processo único pelo qual passam milhares de indivíduos, pois está inserido em um contexto histórico e socialmente inscrito possuindo características tanto individuais quanto coletivas. Individual porque remete às experiências na esfera de trabalho de cada sujeito e coletivo porque é vivenciado por um mesmo grupo profissional de maneira semelhante. Histórico por estar relacionado com a conjuntura econômica, social e política de determinada época e socialmente inscrito, pois é marcado por processos institucionalizados e representações sociais compartilhadas pelos indivíduos de determinado grupo e região sobre o período da inserção profissional (ROCHA DE OLIVEIRA, 2012).

Considerando as colocações acima, podem-se colocar como principais influenciadores do processo de inserção profissional os aspectos individuais, os aspectos institucionais e o contexto sócio histórico.

\begin{tabular}{|c|c|c|}
\hline Inserção Profissional & $\begin{array}{l}\text { Aspectos individuais } \\
\text { Aspectos Institucionais }\end{array}$ & $\begin{array}{l}\text { Estrutura demográfica e ocupacional } \\
\text { Conjuntura econômica } \\
\text { Niveis de formação da mão-de-obra } \\
\text { Desenvolvimento tecnológico e industrial } \\
\text { Origem Familiar } \\
\text { Representações do trabalho } \\
\text { Experiências Profissionais } \\
\text { Expectativas Profissionais } \\
\text { Estratégias de Inserção } \\
\text { Regulamentações Estatais } \\
\text { Políticas Públicas } \\
\text { Políticas de Gestão de RH } \\
\text { Agentes Intermediários } \\
\text { Instituições de Ensino }\end{array}$ \\
\hline
\end{tabular}

Figura 1 - Inserção Profissional

Fonte: ROCHA DE OLIVEIRA, 2012, p. 131

Para explicar a figura acima, Rocha de Oliveira (2012) menciona que dada a sua característica de construção 
social, inscrita em um contexto sociohistórico, a inserção profissional tem como moldura para o ingresso do jovem no mercado de trabalho aspectos da conjuntura econômica, da estrutura demográfica e ocupacional do país ou região, níveis de formação e desenvolvimentos tecnológico e industrial.

Nos aspectos institucionais estão presentes as regulamentações estatais que regulam por meio de leis que definem como deve ocorrer o processo de inserção profissional, limitando idade, formação para cargos específicos e leis que orientam as relações de trabalho e as políticas públicas, sendo mecanismos do governo para lidar com as dificuldades e controle da inserção por meio de programas ou abordagens pontuais focadas em determinado segmento da população. As políticas de gestão das empresas, já mencionadas, influenciando a demanda e oferta para cargos e os tipos de contratos disponíveis. Os agentes intermediários que nas últimas décadas se destacaram com a atuação no mercado de estágios, programas de trainee e consultorias de headhunting e as instituições de ensino, formadoras dos futuros trabalhadores.

Nos aspectos individuais, a origem familiar exerce influência nas condições de construção dos caminhos para a inserção profissional, envolvendo etnia, escolaridade, profissão dos pais, valores considerados pela família sobre o trabalho e elementos que contribuem para a construção de suas representações do trabalho. A experiência profissional remete à biografia da relação do sujeito com o mundo do trabalho, englobando os conhecimentos práticos adquiridos, as frustrações e expectativas criadas a partir da sua trajetória. Com isso, o somatório desses acontecimentos permite a criação das estratégias de inserção

A compreensão sobre a inserção profissional contribui para o entendimento da construção da força de trabalho, para a criação de políticas públicas adequadas e para o desenvolvimento profissional do jovem antes e durante sua atuação no mercado de trabalho.

\section{Trajetórias de Inserção profissional na Administração}

A Administração é o curso de graduação com o maior número de alunos no país, com 858.899 alunos em 2012 segundo dados do Censo da Educação Superior, representando 13\% do total de universitários brasileiros. Na última década, instituições de qualidade duvidosa surgiram em grande número, deparadas com fraca fiscalização por parte das autoridades e impulsionadas pelo crescimento do modo EAD (Ensino a Distância), aumentando o número de bacharéis em Administração. Além de competirem entre si, os futuros administradores precisam enfrentar a concorrência de outros cursos superiores para obter uma vaga de emprego e adotam trajetórias de inserção profissional variadas, que podem ser realizadas de diferentes maneiras.

0 processo de inserção profissional é o momento em que o jovem aprende as regras que organizam 0 mercado de trabalho, o que ocorre muitas vezes ainda durante a formação, transformando as instituições de ensino em importantes atores. É de prática comum a participação dos estudantes de Administração em programas de estágio, programas de trainee, bolsas de iniciação cientifica e Empresas Juniores durante e ao final do curso. São maneiras distintas de buscar uma colocação no mercado de trabalho e cada uma delas contribui de forma diferente para esse objetivo.

"Nota-se que há dois marcos de ingresso no mercado de trabalho para os estudantes do curso de superior em Administração: o primeiro refere-se à experiência que o insere no mundo do trabalho, que muitas vezes é realizado com o auxílio dos pais, familiares ou amigos; o segundo é de construção da carreira e de aprofundamento dos possíveis caminhos futuros." (ROCHA DE OLIVEIRA, 2012, v. 13, no. 2) 
O presente artigo foca nos alunos que iniciam seu ingresso no mundo do trabalho por meio das Empresas Juniores, normalmente ocorrendo nos primeiros semestres do curso visto que é uma atividade não remunerada e que não exige experiência. Destaca-se a importância do primeiro marco para os ingressantes em EJ, que participam da seleção organizada por colegas do curso e dependem, em sua maioria, do apoio familiar para o sustento financeiro. $O$ segundo marco pode ser relacionado à EJ na medida em que 0 aluno, por meio do convívio profissional e das atividades exercidas inicia o processo de escolha dos caminhos que irá seguir na sua carreira e toma o próximo passo baseado em suas vivências na EJ.

\section{Empresas Juniores}

A profissão de administrador é voltada quase que inteiramente para a prática. No entanto, durante a formação do profissional, as instituições de ensino dispõem de amplos recursos pedagógicos para o desenvolvimento e difusão do conhecimento teórico, mas não estabelecem currículos ou atividades que propiciem uma abordagem efetivamente prática. Apesar de ser de grande importância, apenas o conhecimento teórico não é o suficiente para qualificar 0 aluno de Administração além da concorrência, especialmente para o setor privado. O sistema educacional brasileiro, muitas vezes, apenas apresenta as ferramentas gerenciais para seus acadêmicos, não ensinando de que forma elas podem ser aplicadas na prática, restando, assim, uma lacuna de difícil preenchimento (JUNIOR, 2006 apud RODRIGUES et al. 2009). Os alunos então procuram por atividades extra curriculares como alternativa para suprir essa carência durante a graduação e encontram as EJ como opção. As Empresas Juniores são associações civis, sem fins lucrativos, gerenciadas pelos alunos e orientadas por docentes de uma IES. Por meio delas, alunos podem vivenciar e aplicar na prática conhecimentos teóricos em situações organizacionais reais, desenvolver seu senso crítico, analítico e empreendedor e colocá-los em contato direto com o mercado de trabalho. (GUIMARÃES, SENHORAS, TAKEUCHI, 2003). Essas empresas trabalham desenvolvendo projetos de consultoria para clientes (geralmente empresas e empreendimentos de pequeno porte) nas áreas de $\mathrm{RH}$, finanças, marketing e estratégia permitindo que seus integrantes se envolvam com problemas, processos e dinâmicas organizacionais.

A relevância das EJ pode ser observada pela sua difusão pelo país. Segundo dados da Confederação Brasileira de Empresas Juniores, hoje existem cerca de 700 EJ em atuação no Brasil com 22.000 universitários desenvolvendo mais de 2.000 projetos por ano. Como finalidade, as EJ devem:

"Promover o desenvolvimento técnico e acadêmico de seus associados; promover o desenvolvimento econômico e social da comunidade, através de suas atividades; fomentar o espírito empreendedor de seus associados. Promover o contato dos alunos com 0 mercado de trabalho e promover o desenvolvimento pessoal e profissional de seus associados." (CBEJ. 2003)

Vemos então que na EJ o estudante pode desenvolver competências comportamentais, conhecimentos, habilidades e aptidões por meio de negociações com clientes, elaboração de projetos, gestão financeira e de pessoas (as EJ possuem hierarquia de cargos), tudo isso inserido em um contexto real e prático. Assim, podemos analisar se, ao vivenciarem e serem confrontados com a realidade empresarial ainda na graduação, estariam os membros de Empresas Juniores obtendo melhores qualificações, percebendo 0 seu desenvolvimento profissional e encontrando caminhos ou diferenciais para a inserção no mercado de trabalho.

Após o levantamento de conceitos e reflexões sobre o mercado de trabalho e meios de inserção nesse ambiente, é perceptível que o assunto engloba aspectos e mudanças contemporâneas que se desenvolveram 
significativamente nas recentes décadas.

\section{Coleta de dados}

Para coleta de dados foi aplicado um questionário estruturado composto por 5 blocos, cada um com um objetivo específico, questões objetivas e com afirmações dispostas em uma escala Likert de 1 a 5 , variando de "discordo totalmente" a "concordo totalmente". O questionários buscava foi estruturado para alcançar os seguintes objetivos: a) Levantar informações sobre o perfil do respondente e motivações para escolha do curso superior. b) Levantar e analisar as opiniões dos respondentes quanto a contribuição da Universidade para sua formação e preparação para atuação no mercado. c) Levantar e analisar as opiniões dos respondentes quanto a contribuição da Empresa Junior para sua formação, preparação para atuação no mercado e como alternativa para complemento da aprendizagem recebida na Universidade. d)Levantar e analisar as expectativas profissionais futuras dos respondentes para. e) Determinar e analisar a situação atual dos respondentes quanto à posição no mercado de trabalho.

A coleta dos dados foi realizada após entrar em contato por telefone, email e redes sociais com diretores das Empresas Juniores cadastradas na Confederação Brasileira de Empresas Juniores (Brasil Jr.), ocorrendo por meio eletrônico com convites via email enviados aos participantes de EJ de diversos estados brasileiros no qual era indicado um link eletrônico para que pudessem participar da pesquisa. Após o fechamento do questionário, as respostas foram tabuladas e deu-se início a analise dos resultados com a utilização de um software específico no cálculo de médias e porcentagens para servirem de embasamento para as considerações objetivas a respeito da visão dos participantes de EJ sobre as contribuições da universidade de Administração e da própria Empresa Junior na formação e inserção profissional.

\section{Caracterização dos respondentes}

O questionário foi aplicado tanto para integrantes que estão atualmente em uma Empresa Junior quanto para ex-integrantes. Do total de 103 respondentes, 4 já estavam formados. Referente ao gênero, 61 (59,2\%) eram do sexo feminino e $41(40,8 \%)$ do sexo masculino. Os alunos respondentes são oriundos de faculdades conforme tabela abaixo.

\begin{tabular}{|lcc|}
\hline Universidade & Ocorrências & Percentual \\
UFRGS & 23 & $22.3 \%$ \\
Universidade de Brasília & 20 & $19.4 \%$ \\
ESPM RJ & 12 & $11.7 \%$ \\
UFPR & 11 & $10.7 \%$ \\
UFRJ & 9 & $8.7 \%$ \\
UFJF - Universidade Federal de Juiz de Fora & 6 & $5.8 \%$ \\
Universidade Federal do Ceará & 6 & $5.8 \%$ \\
Universidade Estadual de Londrina - UEL & 2 & $1.9 \%$ \\
USP & 2 & $1.9 \%$ \\
UERJ & 1 & $1.0 \%$ \\
UFMG & 1 & $1.0 \%$ \\
Fundação João Pinheiro & 1 & $1.0 \%$ \\
UFRN & 1 & $1.0 \%$ \\
Aespi & 1 & $1.0 \%$ \\
Universidade Estadual do Piauí & 1 & $1.0 \%$ \\
UFBA & 1 & $1.0 \%$ \\
UFSJ & 1 & $1.0 \%$ \\
Universidade Federal do Pampa - Campus Santana do Livramento & 1 & $1.0 \%$ \\
UFMS & 1 & $1.0 \%$ \\
UEM & 1 & $1.0 \%$ \\
Mackenzie & 1 & $1.0 \%$ \\
\hline
\end{tabular}

Tabela 1 - Universidades 


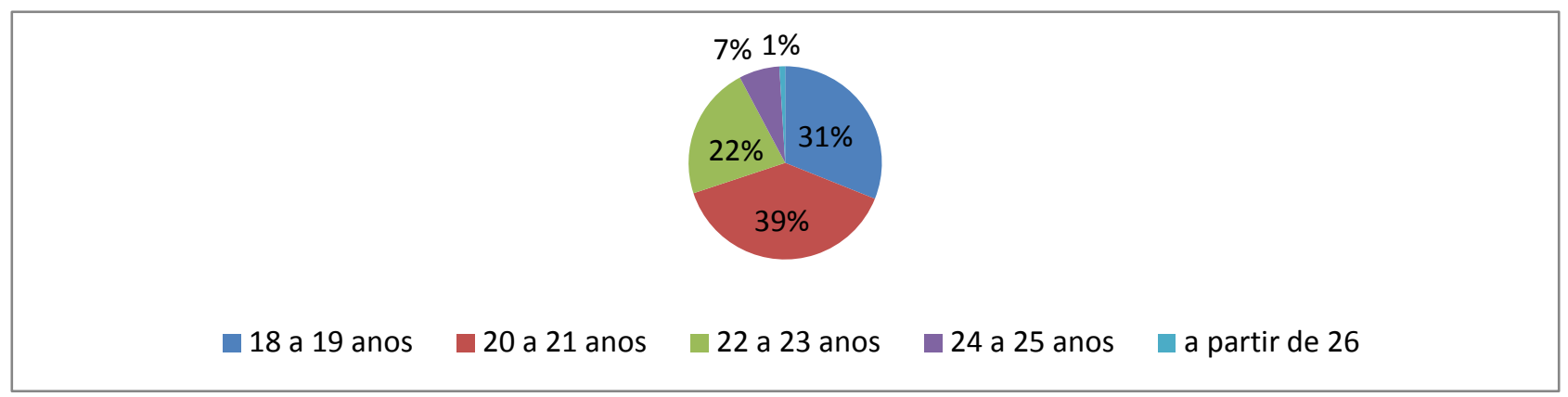

Gráfico 1 - Idade

Referente a situação atual de trabalho, 66 dos respondentes ainda se encontram atuando nas empresas Juniores, 19 já mudaram para outras empresas e 18 estavam sem trabalhar no momento. As Empresas Juniores (EJ), sendo entidades sem fins lucrativos e não oferecendo remuneração para seus integrantes, costumam ser procuradas por alunos ainda no início do curso. Dos respondentes que ainda estão na EJ, $71 \%$ deles estão entre $01^{\circ}$ e $5^{\circ}$ semestre da faculdade, conforme gráfico 3 .

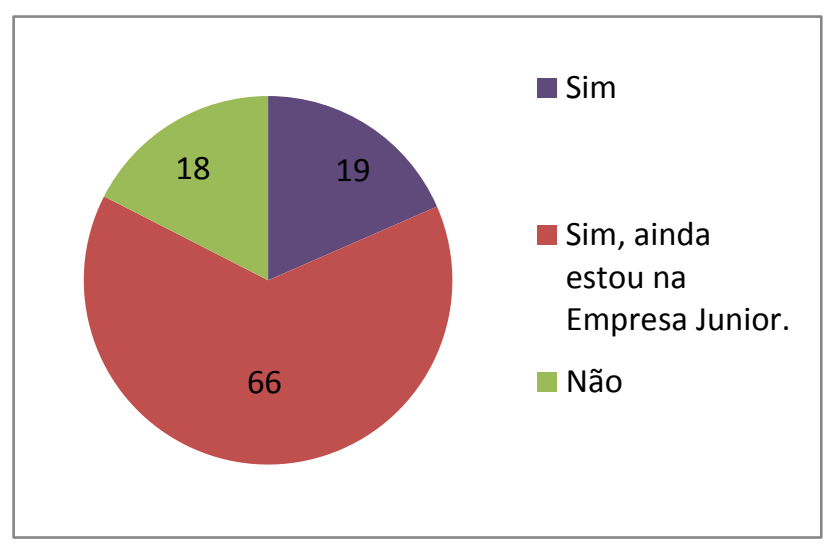

Gráfico 2 - Está trabalhando?

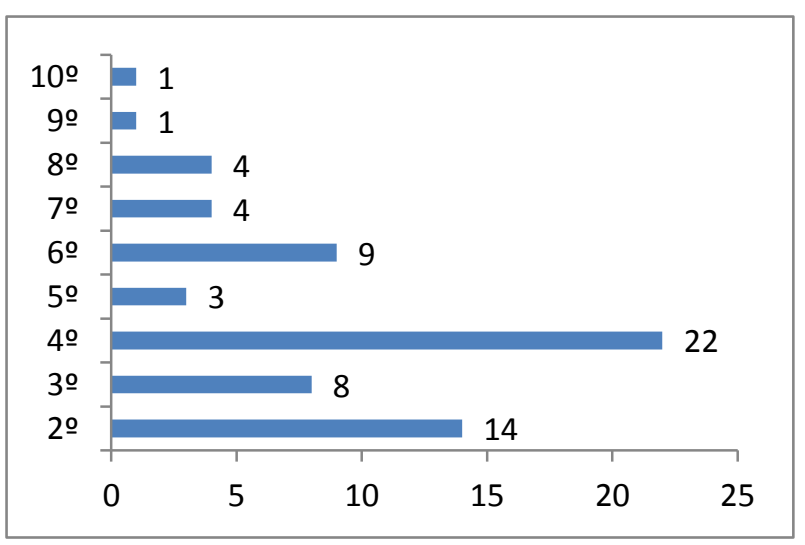

Gráfico 3 - Semestre atual integrantes EJ

Apesar de ser uma atividade não remunerada e a EJ estar vinculada à instituição de ensino, os projetos desenvolvidos por seus integrantes têm finalidade econômica atendendo clientes reais atuantes na economia local.

Os dados do gráfico 3 mostram a busca por uma experiência ligada à atuação profissional pouco após 0 ingresso na universidade (algumas IES não permitem estágios ou outras atividades relacionadas no $1^{\circ}$ semestre). Silva (2010) relata que diante das altas taxas de desemprego atuais entre os jovens e da propagação da ideia de que as dificuldades de inserção no mercado de trabalho advêm da falta de experiência profissional, trabalhar e estudar concomitantemente pode demonstrar uma estratégia de enfrentamento das possíveis adversidades profissionais futuras e uma forma de precaução diante da falta de perspectivas otimistas.

Dos 19 respondentes egressos das EJ e que relataram estar trabalhando, 12 estão atuando em empresas privadas, 5 em órgãos públicos e 2 em ONGs. Com relação ao porte das instituições, 10 são de grande porte (mais de 500 funcionários), 1 de médio porte (100 a 500 funcionários), 5 de pequeno porte (20 a 99 funcionários) e 3 são micro empresas (até 19 funcionários). Referente ao ramo das empresas, 11 atuam com serviços, 3 fazem parte do ramo industrial, 2 do comércio, 2 do governo e 1 atua com pesquisa. 


\section{Abimael Ouro e Ikaro Barreto}

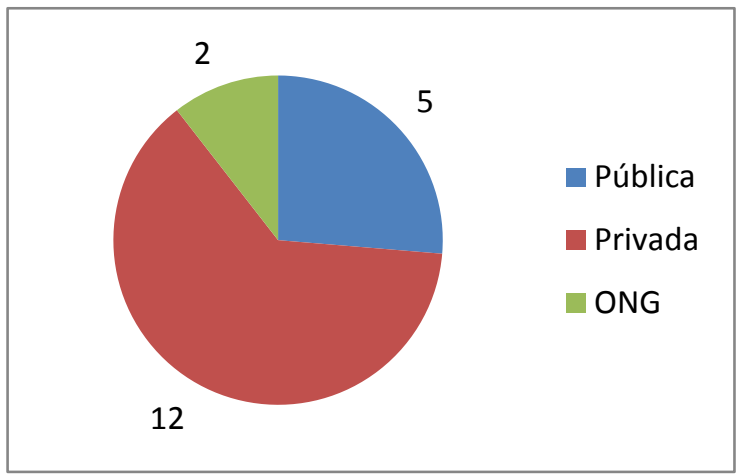

Gráfico 4 - Tipo de Empresa

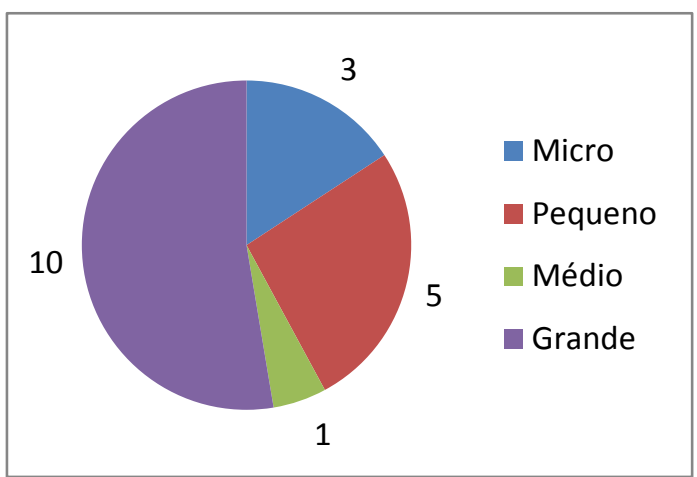

Gráfico 5 - Porte da Empresa

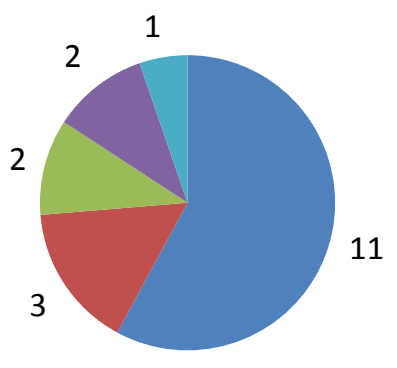

Serviços

Industria

Comércio

Governo

Pesquisa

Gráfico 6 - Ramo da Empresa

O vínculo que possuem com as referidas empresas também foi questionado e estão apresentados no gráfico 12, com as categorias funcionário público, voluntário, empresa familiar, fundador, funcionário de empresa privada (FEPr) com carteira assinada, funcionário de empresa privada (FEPr) sem carteira assinada e estagiário.

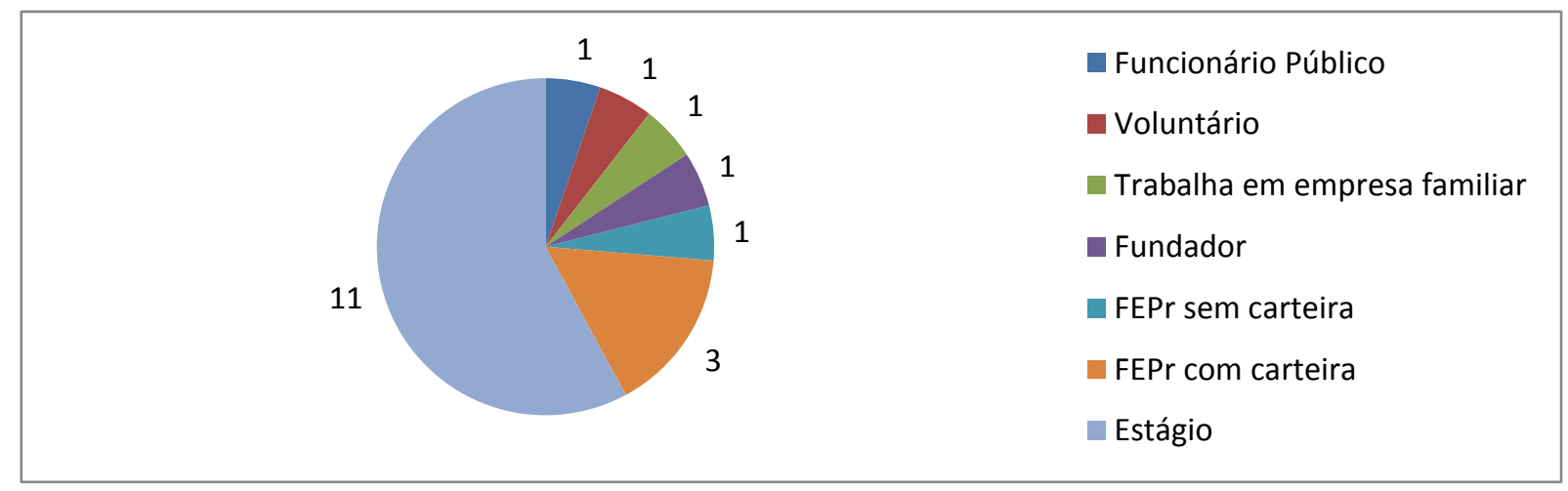

\section{Gráfico 7 - Vínculo com Empresa}

Ainda no primeiro bloco do questionário, os alunos foram perguntados quais eram as suas principais motivações para terem escolhido o curso de Administração, ficando como mais indicadas as respostas "formação abrangente" e "oportunidades de emprego na área", empatadas com 27,5\% cada uma. 


\begin{tabular}{|c|c|}
\hline Principal Motivação & $\%$ de respostas \\
\hline Formação abrangente & $27.50 \%$ \\
\hline Oportunidade de emprego na área & $27.50 \%$ \\
\hline Quero abrir meu negócio & $13.75 \%$ \\
\hline Influência familiar & $12.50 \%$ \\
\hline Motivação financeira & $8.75 \%$ \\
\hline Influência de professores ou escola & $2.50 \%$ \\
\hline Para fazer concurso público & $2.50 \%$ \\
\hline Experiência na área de administração & $2.50 \%$ \\
\hline Trabalhar na empresa da família & $1.25 \%$ \\
\hline Influência da mídia & $1.25 \%$ \\
\hline
\end{tabular}

Tabela 2 - Principal motivação para escolha do curso

Pode-se inferir que a formação abrangente alivia o fator da competitividade, permitindo que 0 administrador tenha a possibilidade de explorar e obter sucesso em áreas profissionais diversas e que também, ao ingressarem na universidade, os jovens ainda não possuem uma ideia concreta sobre onde pretendem atuar. Esta última suposição pode ser corroborada pelas respostas à outra questão do questionário, destacada na tabela 3:

\begin{tabular}{|lccc|}
\hline Afirmação & Moda & Média & Variância \\
$\begin{array}{l}\text { Ingressei no curso de Administração tendo } \\
\text { claro qual seria minha trajetória profissional }\end{array}$ & 1 & 2.11 & 1.49 \\
\hline
\end{tabular}

Tabela 3 - Trajetória profissional

\section{Tabela 3 - Trajetória profissional}

A afirmação possui uma escala de 1 a 5 , sendo 1 para "Discordo totalmente" e 5 para "Concordo totalmente", mostrando que 68 dos respondentes discordavam da afirmação, totalizando $66 \%$ da amostra. Também é possível considerar o conceito de carreiras multidirecionais no qual o profissional não está preso a um único modelo de carreira linear, podendo construí-la em diferentes organizações e em sentidos diversos, ou seja, focada nos objetivos traçados pelos indivíduos (BARUCH, 2004). Sobre esse conceito, Costa e Campos (2006) observam que as trajetórias profissionais não são sempre planejadas, fazendo com que oportunidades apresentadas ao acaso, sejam elas relacionadas ao trabalho ou estudo, influenciem a direção que o indivíduo irá seguir. Essas idéias dão respaldo aos resultados encontrados na afirmação abaixo.

\begin{tabular}{|c|c|c|c|}
\hline Afirmação & Moda & Média & Variância \\
\hline $\begin{array}{l}\text { As oportunidades apresentadas pelo } \\
\text { mercado de trabalho podem mudar meu }\end{array}$ & 4 & 3.98 & 0.58 \\
\hline
\end{tabular}

Tabela 4 - Flexibilidade do planejamento profissional 
Nessa afirmação, 79 respondentes concordaram com ela totalizando $76,6 \%$ dos alunos questionados, mostrando que as trajetórias profissionais estão mais flexíveis e um curso com formação abrangente possibilita isso.

A outra opção mais mencionada quanto à motivação para escolha do curso, "Oportunidade de emprego na área", mostra como antes mesmo de ingressarem no curso, os conceitos de mercado de trabalho e inserção profissional já permeiam a mente dos participantes de EJ. Como causa para esse comportamento podemos destacar: uma maior taxa de desemprego para jovens; o crescimento da competitividade e a busca por qualificação, fazendo com que uma área que tenha maior oferta de emprego seja mais procurada. Com relação à competitividade e qualificação, foram analisadas as seguintes respostas:

\begin{tabular}{|c|c|c|c|}
\hline Afirmação & Moda & Média & Variância \\
\hline $\begin{array}{l}\text { Sinto que criei um diferencial na disputa de vagas no } \\
\text { mercado de trabalho }\end{array}$ & 5 & 4.68 & 0.37 \\
\hline $\begin{array}{l}\text { As empresas privadas valorizam a participação de } \\
\text { estudantes em Empresas Juniores }\end{array}$ & 4 & 4.08 & 0.79 \\
\hline $\begin{array}{l}\text { Sinto-me mais seguro para encarar processos seletivos } \\
\text { devido à experiência adquirida na EJ }\end{array}$ & 5 & 4.52 & 0.56 \\
\hline
\end{tabular}

Tabela 5 - Competitividade e Qualificação

As respostas para as afirmações acima, com altos percentuais de concordância e baixa variância, podem ser relacionadas com a percepção que os integrantes de EJ possuem de seu ambiente. Pela visão de Weale (1992 apud KING; BURKE; PEMBERTON, 2005), podemos criar uma representação do mercado baseada na demanda (analisando as vagas atuais que estão sendo ofertadas e projetando demandas futuras) ou baseada na utilização de colegas e conhecidos como referências (mostrando a oferta disponível). Um indivíduo capaz de conciliar ambas as abordagens estaria se diferenciando no mercado, visto que poderia direcionar seus esforços de qualificação para áreas com pouca oferta e muita demanda.

No Brasil, quando se trata dos processos de ensino-aprendizagem das universidades, uma questão discutida frequentemente é com relação ao peso desproporcional do conhecimento teórico em detrimento das vivências práticas (NUNES, 2009; BORBA, SILVEIRA \& FAGGION, 2008 apud VAZQUEZ, 2012 et al). Neste sentido, Alvarães (2009 apud VAZQUEZ, 2012 et al) conclui que existe a necessidade de estabelecer um elo entre 0 conhecimento científico e o cotidiano, considerando significados práticos associados aos conteúdos ensinados em sala de aula. Portanto, estando a maioria dos alunos de graduação em Administração presos ao modelo teórico de aprendizado, os participantes de EJ, por terem a aprendizagem prática, estariam mais propensos a adquirir um diferencial na disputa por vagas no mercado de trabalho. Também, como citado na introdução, o perfil do candidato de Administração que as empresas buscam atualmente é mais voltado para a capacidade de desenvolvimento de competências. Para Brum (2009 apud DOS-SANTOS et al 2013) é possível pensar na EJ como um espaço que possibilita a criação do conhecimento e um local de desenvolvimento de competências.

A aprendizagem informal, presente no cotidiano das EJ, ocorre em situações não planejadas de ensino, onde os alunos obtêm informações ao mesmo tempo em que aprofundam sua expertise através de experiências enriquecedoras e significativas para lidar com os desafios da prática profissional (RUNGER \& FRENSCH, 2010 apud VAZQUEZ, 2012 et al). Essa aprendizagem e o conhecimento obtido por meio dela pode lhes conferir uma sensação de segurança durante processos seletivos.

A terceira opção que mais apareceu nas respostas foi "Quero abrir meu negócio" como principal motivação para $13,75 \%$ dos respondentes. Segundo dados do Global Entrepreneurship Monitor (GEM), instituição que faz levantamento de dados sobre empreendedorismo, em 2012, 89\% dos entrevistados no Brasil concordaram com a afirmativa "A maioria das pessoas considera que empreender em um negócio é uma 
opção de carreira desejada" e $36,5 \%$ dos entrevistados tem a intenção de iniciar um negócio nos próximos dois anos. Nos anos anteriores, 2010 e 2011 os valores foram 78\% e 26,5\% e 86\% 28,2\% respectivamente, mostrando um aumento nos últimos 3 anos pesquisados. No questionário aplicado aos integrantes de EJ 0 conceito de empreendedorismo foi abordado em algumas outras questões:

\begin{tabular}{|lccc|}
\hline Afirmação & Moda & Média & Variância \\
$\begin{array}{l}\text { Tive acesso à idéias que me permitiram } \\
\text { vislumbrar uma possibilidade de negócio no Brasil }\end{array}$ & 5 & 4.12 & 0.88 \\
\begin{tabular}{l} 
Abrir um negócio próprio \\
\hline
\end{tabular} & 2 & 2.89 & 1.71 \\
\hline
\end{tabular}

Tabela 6 - Empreendedorismo

É possível notar que as atividades exercidas na EJ permitem ao participante que ele veja opções para iniciar um negócio próprio, mas que em outra questão, quando perguntados sobre ações para os próximos anos, a intenção de "Abrir um negócio próprio" aparece com uma média de concordância baixa. Segundo informações do Youth Business International, organização mundial que visa auxiliar jovens a iniciarem e organizarem seu próprio negócio, os jovens ao redor do mundo possuem a vontade, mas não as ferramentas para se tornarem empreendedores.

\section{Contribuições das Universidades}

$\mathrm{Na}$ literatura o administrador é descrito como o profissional responsável por gerir tarefas difíceis e desafiadoras e que muitas vezes precisa encontrar soluções novas e, por isso, faz apelo a inúmeras fontes de conhecimento. Ao confrontar-se com problemas, o Administrador deve ser capaz de identificar as variáveis mais importantes, perceber suas relações principais, aplicar o conhecimento específico exato e selecionar 0 método de solução mais adequado. Em linhas gerais, o Administrador deve ter uma visão global e formação humanística que o habilite a compreender o meio social, político, econômico e cultural onde está inscrito e tomar decisões de um modo diversificado e interdependente (NUNES, BARBOSA, 2003).

No entanto, existem questionamentos quanto ao método de ensino atual, considerando-o engessado e ignorante às mudanças e avanços ocorridos ao longo dos anos, abordando a formação de administradores de modo mecanicista. Nicolini (2003) chega a comparar as escolas de Administração com organizações industriais, as quais a partir de um padrão de produção, determinado por características da escola e necessidades locais, definem a maneira para formar os administradores, escolhem os trabalhadores mais adequados para a tarefa e selecionam a matéria prima (alunos). Colocando em outras palavras ele diz, criticando, que de acordo com esse modelo bastaria ter uma proposta de currículo, um bom corpo docente e bons estudantes, para possibilitar a formação de bons administradores.

O problema de um método de ensino que adota uma fórmula única e padrão, sem modificá-la enquanto outras variáveis do ambiente no qual a instituição está inserida vão sofrendo mudanças é que isso gera uma falta de preparo e uma desconexão com a realidade dos futuros administradores. Hoje, é preciso estar preparado para dar mais do que respostas prontas para problemas costumeiros. $O$ aluno precisa ser incentivado a romper paradigmas, a criar e a ousar em um mundo de complexidade crescente e que se transforma rapidamente (NICOLINI, 2003). Também nesse tema, Motta (1983) identificou o distanciamento do que era ensinado nos cursos de graduação com o que os administradores se deparavam no mundo profissional.

Embora tenha feito uma análise que critica duramente e enfatiza os pontos negativos do sistema de ensino atual, a visão de Nicolini sobre o tema pode ser confirmada, em parte, com o resultado de uma das questões 
aplicadas no questionário do presente trabalho.

\begin{tabular}{|c|c|c|c|c|}
\hline & $\begin{array}{l}\text { Contribuições da Universidade para formação e inserção } \\
\text { profissional }\end{array}$ & Moda & Média & Variância \\
\hline 1 & $\begin{array}{l}\text { A formação recebida na graduação prepara o estudante para ser um } \\
\text { acadêmico }\end{array}$ & 4 & 3.84 & 1.04 \\
\hline 2 & $\begin{array}{l}\text { As disciplinas do curso contribuíram para minha formação } \\
\text { profissional }\end{array}$ & 4 & 3.64 & 0.72 \\
\hline 3 & $\begin{array}{l}\text { A rede de contatos formada na universidade facilitou minha inserção } \\
\text { profissional }\end{array}$ & 3 & 3.59 & 1.19 \\
\hline 4 & $\begin{array}{l}\text { Procuro manter um desempenho elevado durante o curso, pois } \\
\text { acredito que isso me ajudará profissionalmente no futuro }\end{array}$ & 5 & 3.51 & 1.47 \\
\hline 5 & $\begin{array}{l}\text { A formação recebida na graduação prepara o estudante para atuar } \\
\text { em organizações privadas }\end{array}$ & 3 & 3.10 & 1.33 \\
\hline 6 & $\begin{array}{l}\text { A formação recebida na graduação prepara o estudante para atuar } \\
\text { em organizações públicas }\end{array}$ & 3 & 2.94 & 0.87 \\
\hline 7 & Tive suporte da universidade para minha inserção profissional & 2 & 2.88 & 1.46 \\
\hline 8 & $\begin{array}{l}\text { A formação prática recebida durante o curso é adequada para } \\
\text { facilitar a inserção profissional dos alunos }\end{array}$ & 2 & 2.58 & 1.80 \\
\hline 9 & $\begin{array}{l}\text { A formação recebida na graduação prepara o estudante para ser um } \\
\text { empreendedor }\end{array}$ & 1 & 2.26 & 1.57 \\
\hline 10 & $\begin{array}{l}\text { Ingressei no curso de Administração tendo claro qual seria minha } \\
\text { trajetória profissional }\end{array}$ & 1 & 2.11 & 1.49 \\
\hline
\end{tabular}

Tabela7-bloco-b

No item 8 do Bloco B, com média de 2.58, apesar da alta variância, podemos ver que a maioria considera como insuficiente a formação prática recebida durante a graduação. Na EJ os alunos encontram a oportunidade de melhorar esse aspecto da graduação, porém para o ambiente de sala de aula, seriam necessárias mudanças que poderiam começar com uma maior utilização de estudo de casos atuais, tentando aproximar as problemáticas expostas aos alunos com o que eles se deparam na atualidade e saídas de campo na tentativa de voltar o curso mais para as necessidades do mercado.

Essa questão aborda um problema cuja solução deverá se mostrar cada vez mais necessária para o curso de Administração com o passar dos anos, que é a tendência de priorizar o tempo para o trabalho em detrimento do estudo. Por ter maior reconhecimento, o aprendizado prático (por meio do trabalho ou estágio) acaba se tornando mais importante do que o curso universitário, o qual é deixado em segundo plano por grande parte dos estudantes. Isso pode estar ligado com a organização do modo de ensino, desde décadas anteriores, remetendo ao período da ditadura militar onde a aprendizagem é focada no conhecimento prático sendo relegado o estímulo para a reflexão e o livre pensamento. Os cursos de Administração têm surgimento nesse período e até os dias atuais a maior contribuição da preparação para inserção no mercado de trabalho é vista como estando ligada ao aprendizado de diferentes ferramentas gerenciais (ROCHA DE OLIVEIRA, 2009).

Portanto, sem entrar no mérito do que deveria ser mais valorizado (saber teórico ou técnico), o desafio enfrentado pelos cursos de Administração é visível nas respostas do item 8.

Contudo, ao serem questionados sobre a qualidade da formação recebida e as contribuições das disciplinas cursadas para a formação profissional, os resultados foram mais positivos. 


\begin{tabular}{|lcc|}
\hline Avaliação geral da formação recebida & Ocorrências & Percentual \\
\hline Excelente & 22 & $21 \%$ \\
Boa & 49 & $48 \%$ \\
Regular & 28 & $27 \%$ \\
Ruim & 4 & $4 \%$ \\
Péssima & 0 & $0 \%$ \\
Total & 103 & $100 \%$ \\
\hline
\end{tabular}

Tabela 8 - Avaliação do Curso

No item 2, com média de 3.64 e uma variância de 0.72 a maioria $(57,2 \%)$ dos alunos concordam que as disciplinas do curso contribuíram para suas formações profissionais e no item 4 com média 3.51 e variância de 1.47 apenas 52\% concordam que manter um bom desempenho no curso é favorável para o futuro profissional. Em outra questão foi pedido que avaliassem de maneira geral (incluindo todos os aspectos domínio dos conceitos teóricos da área de estudos e a aquisição de cultura universal) a formação recebida tendo como resultado um percentual elevado de avaliações como "Boa" (48\%) e "Excelente" (21\%) enquanto a minoria avaliou como "Regular" $(27 \%)$ e Ruim (4,0\%). Analisando os resultados das afirmações acima, poderia ser inferido que a formação teórica atende as expectativas dos alunos pesquisados, sendo necessário um investimento maior na abordagem prática. No entanto, é preciso cautela com os resultados destas questões, pois a maior parte desses alunos ainda está na primeira metade do curso, sendo possível que mudem suas percepções conforme progridam na graduação.

Indagados sobre o ramo de atuação para o qual sentem que estão sendo preparados pela universidade por meio da formação recebida, notamos que a percepção dos alunos é de que existe um foco para preparação para atuarem no meio acadêmico com uma média de concordância de 3.84 para a afirmação "A formação recebida na graduação prepara o estudante para ser um acadêmico". Em segundo lugar com média de concordância de 3.10 aparece a preparação para atuação em organizações privadas, seguida por atuação em organizações públicas com média de 2.94 e em último, com média de concordância de 2.26 a preparação para atuar como empreendedor.

\begin{tabular}{|lccc|}
\hline Afirmação & Moda & Média & Variância \\
\hline $\begin{array}{l}\text { A formação recebida na graduação prepara o } \\
\text { estudante para ser um acadêmico }\end{array}$ & 4 & 3.84 & 1.04 \\
$\begin{array}{l}\text { A formação recebida na graduação prepara o } \\
\text { estudante para atuar em organizações } \\
\text { privadas }\end{array}$ & 3 & 3.10 & 1.33 \\
$\begin{array}{l}\text { A formação recebida na graduação prepara o } \\
\text { estudante para atuar em organizações } \\
\text { públicas }\end{array}$ & 3 & 2.94 & 0.87 \\
$\begin{array}{l}\text { A formação recebida na graduação prepara o } \\
\text { estudante para ser um empreendedor }\end{array}$ & 1 & 2.26 & 1.57 \\
\hline
\end{tabular}

Tabela 9 - Direcionamento do Curso

As outras perguntas do bloco são referentes à inserção profissional. Mesmo que a maioria dos respondentes não tenha realizado a inserção profissional, é interessante ver a percepção que possuem do processo e a relação dele com a universidade. 


\section{Abimael Ouro e lkaro Barreto}

\begin{tabular}{|c|c|c|c|}
\hline Afirmação & Moda & Média & Variância \\
\hline $\begin{array}{l}\text { A rede de contatos formada na universidade facilitou minha } \\
\text { inserção profissional }\end{array}$ & 3 & 3.59 & 1.19 \\
\hline $\begin{array}{l}\text { Tive suporte da universidade para minha inserção } \\
\text { profissional }\end{array}$ & 2 & 2.88 & 1.46 \\
\hline
\end{tabular}

\section{Tabela 10 - Inserção Profissional e a Universidade}

Ao considerar todos os respondentes, é possível ver que existe maior participação da rede de contatos do que o apoio da universidade para a inserção profissional. No entanto, para se ter uma análise menos distorcida, ao excluir da amostra os alunos que ainda estão nas EJ e selecionar somente os respondentes que já passaram da metade do curso e ingressaram em empregos ou estágios conforme gráfico 8 é possível chegar a outros valores apresentados na tabela 11.

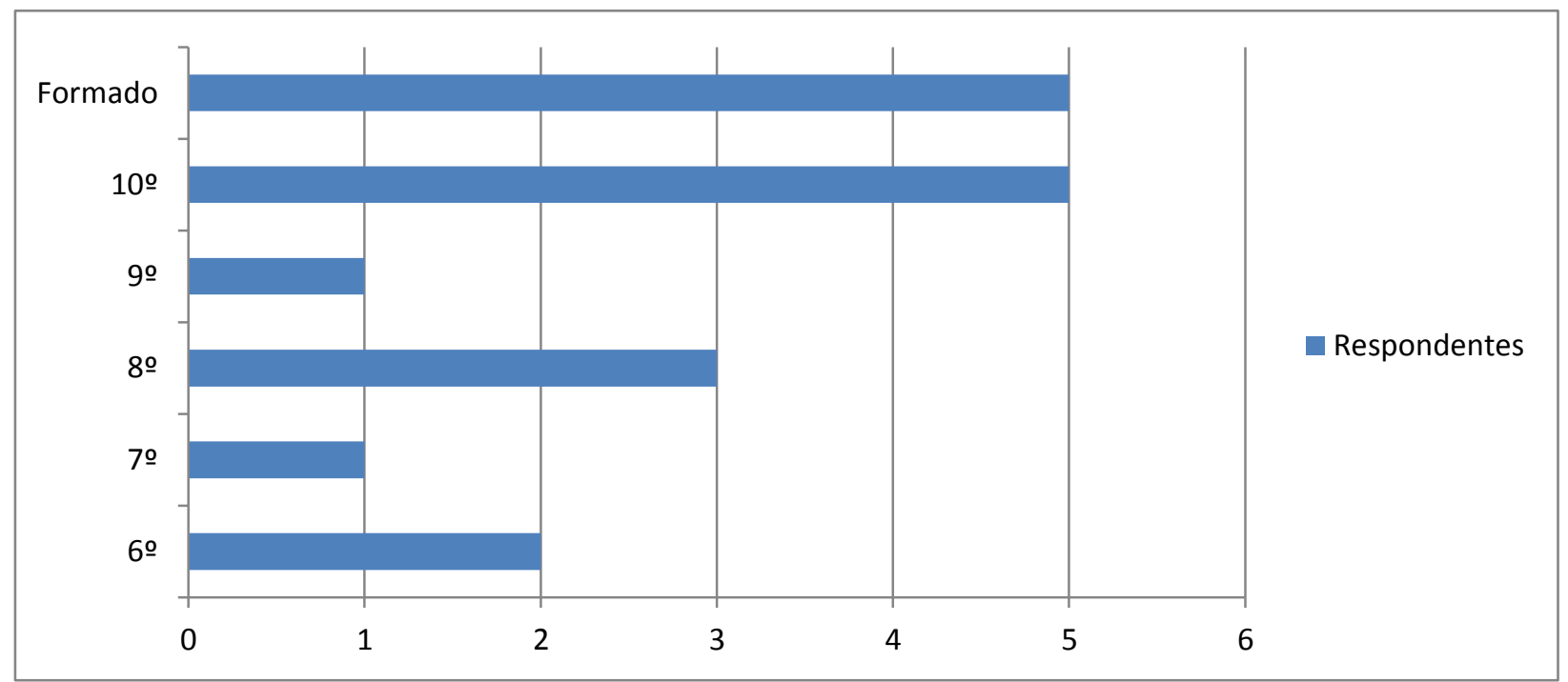

\section{Afirmação}

A rede de contatos formada na universidade facilitou

minha inserção profissional

Tive suporte da universidade para minha inserção profissional

$\begin{array}{crr}\text { Moda } & \text { Média } & \text { Variância } \\ 4 & 4.00 & 0.58 \\ 2 & 2.47 & 1.66\end{array}$

Tabela 11 - Amostra da tabela 10

Vê-se que a opinião dos que já passaram da metade ou concluíram o curso de Administração causa um aumento da amplitude entre as duas afirmações. Dos 17 respondentes incluídos na amostra, 10 deles ainda estão atuando como estagiários. Apesar do estágio não se caracterizar como uma forma de inserção profissional, por estarem perto da conclusão do curso e experimentado por mais tempo a prática da sua profissão, tendo anteriormente passado por uma EJ, suas opiniões seriam baseadas em uma análise mais completa a partir das experiências vividas. Estas experiências tornam-se importantes ao passo que é delas que são formadas as representações do trabalho, retratando como o jovem grava no seu imaginário sua visão de trabalho ao longo de sua vida. Com isso, podem ser analisadas as expectativas do indivíduo e como ele está se preparando para o processo de inserção profissional e a continuidade de sua profissão (ROCHA DE OLIVEIRA, 2009). 
Apesar da maior parte dos questionados ainda não terem realizado a inserção profissional, uma das questões do bloco $\mathrm{E}$ foi referente ao método de obtenção da ocupação atual. Retirando os que não estão trabalhando, os maiores percentuais de resposta foram os de "Indicação de colega da faculdade" com $47,1 \%$ seguido de "Divulgação na faculdade" com 38,8\%. Se retirarmos os 68 respondentes que ainda estão na EJ, mantendo apenas estagiários ou funcionários de empresas/instituições (19) independente do semestre, a opção mais selecionada se mantém como "Indicação de colega da faculdade" com 36,8\% seguida por "Anúncio (Jornal,mural)" com $26,3 \%$ e as demais alternativas conforme tabela 13.

\begin{tabular}{l|cc|}
\hline Como obteve informações/contato sobre sua ocupação atual? & Ocorrências & Percentual \\
\hline Não estou trabalhando & 18 & - \\
Indicação de colega da faculdade & 40 & $47,1 \%$ \\
Divulgação na faculdade & 33 & $38,8 \%$ \\
Anúncio (jornal,mural) & 5 & $5,9 \%$ \\
Indicação de conhecidos e familiares & 2 & $2,4 \%$ \\
Empresa familiar & 2 & $2,4 \%$ \\
Anúncio mídias sociais & 2 & $2,4 \%$ \\
Agência de emprego/estágio & 1 & $1,2 \%$ \\
Currículo enviado à empresa & 0 & $0,0 \%$ \\
\hline TOTAL & 85 & $100 \%$ \\
\hline
\end{tabular}

Tabela 12 - Obtenção da Ocupação Atual

$\begin{array}{lcc}\text { Como obteve informações/contato sobre seu emprego atual? } & \text { Ocorrências } & \text { Percentual } \\ \text { Indicação de colega da faculdade } & 7 & 36,8 \% \\ \text { Anúncio (jornal,mural) } & 5 & 26.3 \% \\ \text { Anúncio mídias sociais } & 2 & 10.5 \% \\ \text { Empresa familiar } & 2 & 10.5 \% \\ \text { Indicação de conhecidos e familiares } & 1 & 5.3 \% \\ \text { Agência de emprego/estágio } & 1 & 5.3 \% \\ \text { Divulgação na faculdade } & 1 & 5.3 \% \\ \text { Currículo enviado à empresa } & 0 & 0.0 \% \\ \text { TOTAL } & 19 & \mathbf{1 0 0 \%}\end{array}$

Tabela 13 - Amostra tabela 12

Podemos concluir que a rede de contatos é uma ferramenta de significativa importância para a inserção profissional e que mesmo não sendo identificada uma concordância com o suporte da universidade na inserção profissional dos alunos, indiretamente 0 ambiente universitário proporciona a construção de uma rede de contatos que futuramente torna-se útil e vantajosa.

Por meio da análise dos resultados do Bloco $\mathrm{B}$, vemos que a universidade, no que tange a inserção profissional, é percebida como um meio para a construção de uma rede de contatos, agregadora de conhecimentos teóricos úteis para a formação que é, de maneira geral, considerada boa. No entanto, no que se refere à aprendizagem prática, as IES de Administração deixam muito a desejar. 


\section{Abimael Ouro e lkaro Barreto}

\section{Contribuições das Empresas Juniores}

Para avaliar as contribuições das EJ, o questionário continha as seguintes afirmações:

\begin{tabular}{|c|c|c|c|c|}
\hline & Contribuições da EJ para formação e inserção profissional & Moda & Média & Variância \\
\hline 1 & $\begin{array}{l}\text { Sinto que criei um diferencial na disputa de vagas no mercado } \\
\text { de trabalho }\end{array}$ & 5 & 4.68 & 0.37 \\
\hline 2 & $\begin{array}{l}\text { Na EJ aprendi conteúdos aos quais eu não teria acesso na } \\
\text { sala de aula }\end{array}$ & 5 & 4.54 & 0.62 \\
\hline 3 & $\begin{array}{l}\text { Sinto-me mais seguro para encarar processos seletivos devido } \\
\text { à experiência adquirida na EJ }\end{array}$ & 5 & 4.52 & 0.56 \\
\hline 4 & $\begin{array}{l}\text { Incentivou-me a buscar possibilidades de formação } \\
\text { complementares às disciplinas cursadas na graduação }\end{array}$ & 5 & 4.47 & 0.56 \\
\hline 5 & $\begin{array}{l}\text { Ter participado de uma EJ foi de grande importância para } \\
\text { minha inserção profissional }\end{array}$ & 5 & 4.40 & 0.80 \\
\hline 6 & $\begin{array}{l}\text { A experiência em uma EJ facilita a inserção profissional em } \\
\text { grandes empresas }\end{array}$ & 5 & 4.31 & 0.70 \\
\hline 7 & $\begin{array}{l}\text { Adquiri uma boa rede de contatos devido a minha participação } \\
\text { na EJ }\end{array}$ & 5 & 4.30 & 0.70 \\
\hline 8 & $\begin{array}{l}\text { Reconheço que os egressos de EJ são exemplos de trajetórias } \\
\text { profissionais a seguir }\end{array}$ & 5 & 4.21 & 0.89 \\
\hline 9 & $\begin{array}{l}\text { Tive acesso à idéias que me permitiram vislumbrar uma } \\
\text { possibilidade de negócio no Brasil }\end{array}$ & 5 & 4.12 & 0.88 \\
\hline 10 & $\begin{array}{l}\text { Pretendo utilizar a rede de contatos adquirida na EJ para } \\
\text { desenvolvimento de carreira }\end{array}$ & 4 & 4.11 & 1.05 \\
\hline 11 & $\begin{array}{l}\text { As empresas privadas valorizam a participação de estudantes } \\
\text { em Empresas Juniores }\end{array}$ & 4 & 4.08 & 0.37 \\
\hline 12 & A EJ permitiu desenvolver meu potencial empreendedor & 4 & 4.05 & 0.82 \\
\hline 13 & $\begin{array}{l}\text { As oportunidades apresentadas pelo mercado de trabalho } \\
\text { podem mudar meu planejamento profissional }\end{array}$ & 4 & 3.98 & 0.58 \\
\hline 14 & $\begin{array}{l}\text { Pretendo utilizar a rede de contatos adquirida na EJ na } \\
\text { construção de negócios futuros }\end{array}$ & 4 & 3.69 & 0.74 \\
\hline 15 & $\begin{array}{l}\text { Já tive vantagens em processos seletivos por ter participado de } \\
\text { uma Empresa Junior }\end{array}$ & 3 & 3.55 & 1.57 \\
\hline 16 & $\begin{array}{l}\text { A participação na EJ permitiu que eu delineasse com clareza } \\
\text { meu futuro profissional }\end{array}$ & 2 & 3.48 & 1.01 \\
\hline 17 & $\begin{array}{l}\text { Não acredito ter agregado conhecimentos práticos } \\
\text { significativos durante minha participação em uma EJ }\end{array}$ & 1 & 1.23 & 0.51 \\
\hline 18 & $\begin{array}{l}\text { Trabalhar em uma EJ foi uma perda de tempo para meu } \\
\text { desenvolvimento profissional }\end{array}$ & 1 & 1.13 & 0.30 \\
\hline
\end{tabular}

Além de médias altas, verifica-se, também, uma baixa variância na maior parte das respostas. Mussak (2003 apud CARVALHO, STRALIOTTO, 2011) afirma que mudaram as características e qualidades dos trabalhadores valorizadas pelo mercado de trabalho. Ele cita oito atributos importantes para o trabalhador do século XXI: flexibilidade, criatividade, informação, comunicação, responsabilidade, empreendedorismo, sociabilização e tecnologia. Dessas, o autor enfatiza que duas - flexibilidade e criatividade - tendem a ser 
mais valorizadas do que os conhecimentos e os diplomas. A EJ por ser uma organização prestadora de serviços de consultoria requer de seus integrantes soluções para problemas apresentados por clientes e com prazos para atendê-los. Ali, jovens estudantes, em sua maioria com pouca experiência na vivência empresarial, têm a oportunidade de se envolver com os problemas, processos e dinâmicas organizacionais (VAZQUEZ et al, 2012).

De posse das respostas, ao analisar os resultados das afirmações 1, 3, 5, 6 e 15, é possível inferir que a EJ é um ambiente apropriado para o desenvolvimento da flexibilidade e criatividade.

A possibilidade de desenvolvimento de novos conhecimentos, características, qualidades e idéias voltadas para a inovação são apontadas como contribuições das EJ tanto por autores em pesquisas sobre 0 assunto quanto nos resultados dessa pesquisa nas afirmações $2,4,9$, e 12.

Souza (2002) destaca o potencial de riqueza para o aprendizado que existe nas EJ ao atribuir aos seus integrantes responsabilidades muito grandes quando comparadas aos estágios oferecidos por empresas sendo que estes são considerados como a principal porta de entrada para o mercado de trabalho ao se tratar de universitários.

Enfrentamos hoje uma realidade organizacional a qual demanda administradores que tenham desenvolvido a capacidade de reconhecer e definir problemas, chegando a soluções por meio do pensamento estratégico e da criatividade, demonstrando iniciativa, vontade de aprender e habilidades de negociação (Comissão de Especialistas de Ensino de Administração, 1997 apud Nicolini, 2003 p.51).

As afirmações relacionadas a aprendizado e incentivo à busca de novos conhecimentos apresentam médias acima de 4 com destaque para "Na EJ aprendi conteúdos aos quais eu não teria acesso na sala de aula" com 4.54 e 0.62 de variância. Para os estudantes de administração, a utilização de um modelo de ensino passivo que não integra teoria e técnica afeta a capacidade de inter-relacionar estes dois conceitos. Para Graça e Pais (2003 apud DOS-SANTOS et al, 2013), a articulação entre teoria e prática faz emergir questionamentos e dúvidas dando ao aprendizado um significado compartilhado, pois há uma real produção de conhecimento, contextualizado com a prática, ao invés de uma mera reprodução do conhecimento.

Souza (2002) complementa que um dos motivos para a aprendizagem ocorrer de maneira diferente do que a realizada em sala de aula ou em estágios é o ambiente de trabalho dentro das EJ, predominantemente informal, organizado e constituído exclusivamente pelos próprios alunos, realizando entre si uma troca de experiências e de atributos pessoais promovendo um estímulo a um espírito de equipe e ao espírito empreendedor, o que não é observado na grande maioria das organizações do mercado. Isso poderia explicar 0 alto índice de concordância com as afirmações 4, 9 e 12 e também pode estar relacionado com 0 aproveitamento dos recursos financeiros gerados pela EJ que apesar de não remunerar seus integrantes, investe parte do lucro obtido com os projetos desenvolvidos na empresa na realização de treinamentos voltados para qualificação com organizações conceituadas por meio de convênios e também em encontros nacionais de participantes de EJ onde ocorre a troca de experiências e conhecimentos adquiridos.

Outra contribuição da EJ que podemos analisar ocorre quando são cruzadas as afirmações mostradas na tabela 15. É possível verificar que dos 68 respondentes que concordaram em ter ingressado no curso de Administração sem ter clareza quanto a sua trajetória profissional, $30(44,12 \%)$ deles conseguiram definir esse aspecto. Infere-se então que por meio das experiências vivenciadas na EJ, uma parcela significativa de alunos consegue definir de certa maneira, um esboço inicial de uma trajetória profissional. 


\begin{tabular}{|c|c|c|c|c|c|c|c|}
\hline & & \multicolumn{5}{|c|}{$\begin{array}{l}\text { 11. A participação na EJ permitiu que eu delineasse com } \\
\text { clareza meu futuro profissional }\end{array}$} & \multirow[b]{2}{*}{ TOTAL } \\
\hline & & 1 & 2 & 3 & 4 & 5 & \\
\hline \multirow{5}{*}{$\begin{array}{l}\text { 9. Ingressei no curso de } \\
\text { Administração tendo } \\
\text { claro qual seria minha } \\
\text { trajetória profissional. }\end{array}$} & 1. Discordo totalmente & 1 & 5 & 19 & 14 & 6 & 45 \\
\hline & 2 & 1 & 2 & 10 & 8 & 2 & 23 \\
\hline & 3 & 1 & 1 & 6 & 8 & 4 & 20 \\
\hline & 4 & 1 & 0 & 3 & 3 & 2 & 9 \\
\hline & 5. Concordo totalmente & 1 & 0 & 1 & 2 & 2 & 6 \\
\hline \multicolumn{2}{|l|}{ TOTAL } & 5 & 8 & 39 & 35 & 16 & 103 \\
\hline
\end{tabular}

Tabela 15 - Trajetória Profissional

Conclui-se que a participação em uma EJ é, para a grande maioria, uma experiência válida, recompensadora e significativa com um aprendizado mais alinhado com as demandas do mercado de trabalho e das organizações inseridas nele quando comparada com as IES. Também serve como um ambiente utilizado para ampliação da rede de contatos, que pode vir a auxiliar na inserção profissional ou na criação de novos negócios.

O próximo passo foi analisar as respostas referentes às expectativas profissionais dos integrantes de EJ de Administração.

\section{Expecativas profissionais}

Foram feitas afirmações para verificar o que os participantes de EJ têm planejado para os próximos anos, que ações pretendem realizar quanto ao rumo profissional em busca de qualificações ou oportunidades de emprego, além de levantar as áreas de atuação da Administração pretendidas por eles.

\begin{tabular}{|c|lccc|}
\cline { 2 - 5 } \multicolumn{1}{c|}{} & Ações para os próximos anos & Moda & Média & Variância \\
\hline 1 & Fazer intercâmbio com foco em aprimoramento profissional & 5 & 3.99 & 1.12 \\
2 & Fazer um curso de especialização & 4 & 3.95 & 0.94 \\
3 & Trabalhar em uma empresa de médio ou grande porte & 4 & 3.87 & 1.12 \\
4 & Fazer seleções para trainee & 4 & 3.62 & 1.52 \\
5 & Fazer um curso de mestrado & 3 & 3.38 & 1.48 \\
6 & Mudar de país em busca de novas oportunidades & 4 & 3.00 & 1.84 \\
7 & Abrir um negócio próprio & 2 & 2.89 & 1.71 \\
8 & Mudar de cidade (no Brasil) para buscar melhores & 3 & 2.73 & 1.77 \\
9 & oportunidades & 3 & 2.31 & 1.96 \\
10 & Frestar concurso público & 1 & 1 & 2.31 \\
11 & Buscar ajuda profissional para orientação de carreira & 2 & 2.30 & 1.73 \\
12 & Ingressar na carreira acadêmica & 1 & 2.04 & 1.30 \\
\hline
\end{tabular}

Tabela 16 - Bloco D 


\begin{tabular}{lc|c}
\hline Em que área da Administração pretende atuar? & Ocorrências & Percentual \\
\hline Marketing & 28 & $27,2 \%$ \\
Recursos Humanos & 18 & $17,5 \%$ \\
Finanças & 18 & $17,5 \%$ \\
Consultoria & 13 & $12,6 \%$ \\
Comercial / Vendas & 7 & $6,8 \%$ \\
Indeciso & 7 & $6,8 \%$ \\
Produção & 6 & $5,8 \%$ \\
Empreendedorismo & 2 & $1,9 \%$ \\
Mercado de Capitais & 2 & $1,9 \%$ \\
Sistemas da Informação & 1 & $1,0 \%$ \\
Logística / Compras / Distribuição & 1 & $1,0 \%$ \\
Total & 103 & $100 \%$
\end{tabular}

Tabela 17 - Área da Administração

As médias das afirmações do bloco $D$ possuem considerável variação, mostrando preferência por determinados objetivos. Em destaque tem-se "Fazer intercâmbio com foco em aprimoramento profissional" com média de 3,99 e variância de 1,12 e "Fazer um curso de especialização" com média de 3,95 e variância de 0,94 seguidas por "Trabalhar em uma empresa de médio ou grande porte" com média de 3,87 e variância de 1,12 e "Fazer seleções para trainee" com média 3,62 e variância de 1,52.

Segundo Pochmann (1998, p.42 apud SILVA, 2010 p.248):

"a escola parece se transformar, algumas vezes, em uma espécie de refúgio temporário do jovem diante do quadro de generalizada escassez de emprego, (...) uma estratégia oculta de disputa por uma vaga, uma das marcas do novo padrão instável e competitivo de inserção ocupacional".

A alta competitividade do mercado induz os futuros profissionais a adotar uma estratégia de capacitação prolongada, permanecendo mais tempo nas instituições de ensino, seja em busca de qualificações que os colocariam à frente de uma grande parcela da população ou por acreditarem que estão se capacitando para atender às demandas do setor produtivo:

"Pode-se concluir que o efeito "antecipador" da ida para o mercado de trabalho, combinado ao efeito "retardador" da saída do sistema de ensino, faz parte de um mesmo processo que tende a caracterizar a inserção profissional dos jovens na atualidade." (SILVA, 2010, p.250)

Isso possibilita inferir que o efeito "antecipador" da ida para o mercado de trabalho combinado com o efeito "retardador" da saída do sistema de ensino analisados por Silva (2010) poderiam ocorrer com os alunos questionados já que duas das maiores médias envolvem permanecer por mais tempo em instituições voltadas para aprendizagem e qualificação, enquanto a terceira trata do ingresso em uma grande empresa, as quais raramente contratam sem que o candidato, antes de terminar a graduação, tenha vivenciado experiências profissionais sólidas.

A expectativa de obter maior qualificação também pode estar ligada ao desejo de obter melhor remuneração. Ao relacionar a renda bruta familiar dos respondentes pesquisados nesse trabalho com o grau de escolaridade dos pais (tabela 19), confirma-se que existe uma associação entre essas variáveis. De acordo com um estudo de Lemos, Dubeux e Pinto (2011) que envolveu relacionar o nível de educação dos pais dos alunos de uma IES privada com a renda familiar obtida, foi observado que um maior nível escolar não determina, mas possibilita uma obtenção de renda mais elevada. Isso pode, em parte, justificar a tendência de prolongação dos estudos em busca de maiores qualificações, podendo ser analisada como uma estratégia para garantir um piso de remuneração de acordo com a expectativa de classe social almejada pelo indivíduo. 


\begin{tabular}{|lrc|}
\hline Assinale a opção que corresponde ao grau de escolaridade de seus pais: & Ocorrências & Percentual \\
\hline Nenhum & 1 & $1.0 \%$ \\
Ensino Fundamental Completo & 6 & $5.8 \%$ \\
Ensino Médio Completo & 22 & $21.4 \%$ \\
Ensino Superior Completo & 45 & $43.7 \%$ \\
Pós Graduação & 19 & $18.4 \%$ \\
Mestrado & 5 & $4.9 \%$ \\
Doutorado & 5 & $4.9 \%$ \\
Total & 103 & $100 \%$ \\
\hline
\end{tabular}

Tabela 18 - Nível de Escolaridade dos Pais

\begin{tabular}{|c|c|c|c|c|c|c|c|}
\hline Renda & Nenhum & Fundamental & Médio & Superior & Pós Grad. & Mestrado & Doutorado \\
\hline Até $\mathrm{R} \$ 1.000$ & & 1 & & & & & \\
\hline Entre $R \$ 1.001$ e $R \$ 2.000$ & & 1 & 1 & & & & \\
\hline Entre $R \$ 2.001$ e $R \$ 3.000$ & 1 & & 1 & & & & \\
\hline Entre $R \$ 3.001$ e $R \$ 5.000$ & & 2 & 3 & & & & \\
\hline Entre $R \$ 5.001$ e $R \$ 9.000$ & & 2 & 6 & 2 & & & \\
\hline Entre $\mathrm{R} \$ 9.001$ e $\mathrm{R} \$ 13.000$ & & & 8 & 10 & 2 & & \\
\hline Entre $R \$ 13.001$ e $R \$ 17.000$ & & & 3 & 18 & 9 & 1 & 1 \\
\hline Entre $R \$ 17.001$ e $R \$ 20.000$ & & & & 7 & 5 & 2 & 3 \\
\hline Mais de $R \$ 20.000$ & & & & 8 & 3 & 2 & 1 \\
\hline Ocorrências & 1 & 6 & 22 & 45 & 19 & 5 & 5 \\
\hline
\end{tabular}

Tabela 19 - Nível de Escolaridade x Renda dos Pais

Para suprirem essa demanda por maiores qualificações, a maioria dos respondentes desta pesquisa têm a intenção de realizar um intercâmbio para aprimoramento profissional. 0 intercâmbio, seja ele com foco profissional ou acadêmico, possibilita ao intercambista o convívio com outra(s) cultura(s) e idioma(s) por meio do relacionamento com pessoas de outra nacionalidade, o que pode agregar conhecimentos e habilidades importante para o seu futuro profissional. Essa experiência internacional também é valorizada pelo mercado de trabalho e por empresas multinacionais, que tendem a ser de grande porte. Como a nova carreira configura-se como um contínuo processo de aprendizagem, é preciso aprender maneiras de desenvolver autoconhecimento e adaptabilidade (Hall 1996), e tais habilidades podem ser desenvolvidas ao residir no exterior.

Entre atuar no setor público, privado, área acadêmica ou empreender os resultados das afirmações indicam uma maior expectativa para o exercício da profissão no setor privado, seguido por empreender, depois atuar no serviço público e por último na carreira acadêmica, conforme mostra o gráfico 9 onde aparecem os números de concordantes para as afirmações $3,7,9$ e 12 da Tabela 16, relacionadas às áreas pretendidas. Isso contrasta com resultados analisados no bloco B onde a maioria dos respondentes considera que as IES são mais voltadas para a formação de acadêmicos, indicando um conflito entre o desejado pelos alunos e 0 oferecido pela universidade, aumentando as chances de que os respondentes que ainda estão na graduação coloquem os estudos em segundo plano e venham a priorizar o trabalho. 


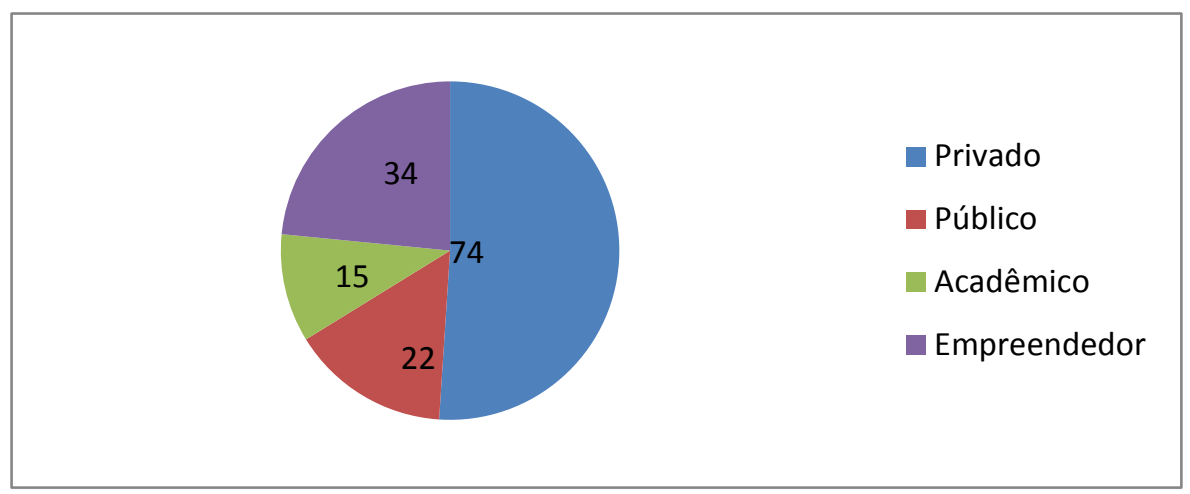

Gráfico 9 - Setores de atuação

A afirmação "Fazer novo curso de graduação" possui uma das médias mais baixas do bloco com 2,31 e 1,73 de variância, possivelmente devido ao fato de que a maioria dos respondentes ainda não passou da metade do curso atual sendo natural que ainda não almejem buscar outra formação. Outro fator que pode influenciar o resultado dessa afirmação é a maior valorização pelo mercado dos trabalhadores que buscam se especializarem em suas profissões do que portadores de dois diplomas de curso superior.

Um resultado curioso ocorre com a quinta média mais alta do bloco, "Fazer um curso de mestrado" com média de 3,38 e variância de 1,48. Mesmo não sendo uma média de concordância alta, 48 (46,6\%) respondentes concordam com a afirmação enquanto apenas $26(25,2 \%)$ discordam. A conciliação de um mestrado com um emprego em tempo integral é bastante desafiadora, e as áreas com maior valorização pela obtenção de um mestrado aparecem no fim da lista do Bloco D que são "Ingressar na carreira acadêmica" em último com média de 2,04 e "Prestar concurso público" com média de 2,31.

Ao cruzar as afirmações 3 e 5 da tabela 16 vê-se que dos 74 que concordam em atuar em uma empresa de médio ou grande porte, $34(45,9 \%)$ pretendem também seguir em busca de um mestrado, porém desconsideram atuar nas áreas em que isso Ihes traria maior retorno. Supõe-se que os esforços para qualificação de alguns respondentes não estejam orientados para que dêem o melhor retorno possível.

\begin{tabular}{|c|c|c|c|c|c|c|c|}
\hline & & \multicolumn{5}{|c|}{ 5. Fazer um curso de mestrado } & \multirow[b]{2}{*}{ TOTAL } \\
\hline & & 1 & 2 & 3 & 4 & 5 & \\
\hline \multirow{5}{*}{$\begin{array}{l}\text { 3. Trabalhar em uma } \\
\text { empresa de médio ou } \\
\text { grande porte }\end{array}$} & 1. Discordo totalmente & 0 & 1 & 0 & 2 & 1 & 4 \\
\hline & 2 & 0 & 3 & 0 & 2 & 3 & 8 \\
\hline & 3 & 0 & 4 & 7 & 5 & 1 & 17 \\
\hline & 4 & 5 & 5 & 11 & 11 & 10 & 42 \\
\hline & 5. Concordo totalmente & 2 & 6 & 11 & 4 & 9 & 32 \\
\hline \multicolumn{2}{|l|}{ TOTAL } & 7 & 19 & 29 & 24 & 24 & 103 \\
\hline
\end{tabular}

Tabela 20 - Cruzamento entre as afirmações 3 e 5

Esse resultado chama a atenção para a segunda média mais baixa do bloco "Buscar ajuda profissional para orientação de carreira" com média de 2,30 e variância de 1,30. Analisando a grade curricular do curso de Administração das universidades com mais respondentes do presente trabalho, Universidade Federal do Rio Grande do Sul (23), Universidade de Brasília (20), ESPM (12), Universidade Federal do Paraná (11) e Universidade Federal do Rio de Janeiro (9) é notada a ausência de conteúdos relacionados a Gestão de Carreira com exceção da UFPR que possui uma cadeira sobre o assunto no $3^{\circ}$ semestre e da UNB que disponibiliza uma cadeira opcional para os alunos. É possivel inferir que uma gestão de carreira poderia 


\section{Abimael Ouro e lkaro Barreto}

auxiliar os alunos, também em outros casos, a direcionarem seus esforços para os fins que tenham o maior retorno de acordo com seus perfis.

A questão representada na tabela 17 serve para demonstrar a diversidade de perfis presentes na EJ. Apesar de atuarem com projetos de consultoria, os serviços prestados são focados em diferentes áreas da Administração como RH, Finanças, Marketing e Empreendedorismo, possibilitando que o Empresário Junior tenha contato com esses segmentos e opte por futuramente seguir atuando em um deles. Com isso, a EJ se apresenta, em parte, como um possível direcionador de carreira permitindo que os seus integrantes por meio da vivência ocorrida nela adquiram autoconhecimento e se identifiquem com uma área da Administração. Segundo Bosley et al (2009) o autoconhecimento permite que o sujeito crie um autoconceito de carreira, que seria uma autoimagem formada à medida que a carreira se desenvolve.

\section{Considerações finais}

O mercado de trabalho passou por significativas mudanças desde o surgimento das escolas de Administração brasileiras, modificando a dinâmica organizacional das empresas e instituições atuantes e moldando as interações entre a sociedade e os mecanismos de inserção profissional.

A percepção do autor deste artigo é de que a formação acadêmica do curso de administração não possui ênfase suficiente no aprendizado prático e por isso, foram escolhidos como população alvo do estudo os participantes de Empresas Juniores. A intenção foi analisar se esses estudantes, por meio do aprendizado prático, poderiam obter vantagens competitivas ou desenvolver competências durante a graduação que os diferenciassem dos demais colegas na disputa por uma vaga no mercado de trabalho.

Fica evidente que os alunos que ingressam na EJ são em sua maioria pertencentes a classes sociais privilegiadas quando comparados com o restante da população brasileira, com 90,2\% dos participantes indicando ter uma renda familiar bruta acima de $\mathrm{R} \$ 5.000$ e com $94,17 \%$ tendo ingressado no ensino superior por meio do acesso universal. A falta de remuneração pela atividade exercida na EJ evidencia a necessidade do suporte financeiro da família durante esse período.

As motivações encontradas para o ingresso na Administração, por um lado, demonstram razões vagas para a escolha do curso, não sendo necessário que o aluno se identifique com a área para realizar a escolha, o que pode reforçar a idéia de que muitos escolhem a Administração por "falta de opção" ou por "não saberem o que querem" e por outro lado talvez indiquem uma tentativa de fuga das formações que limitam a atuação do formando para poucas áreas, aumentando a competitividade. Em suma, o perfil do participante de EJ obtido com a pesquisa parece não fugir do esperado de universitários inscritos em universidades de ponta do Brasil.

$\mathrm{Na}$ análise feita para avaliar como eram percebidas as contribuições da universidade, verificou-se uma satisfação com a formação oferecida e os conteúdos adquiridos em sala de aula foram avaliados pela maioria como agregadores para a formação profissional. No entanto $89 \%$ dos respondentes afirmaram que na EJ foi possível adquirir conhecimentos não vistos em sala de aula e 50\% concordaram que por meio dela, conseguiram delinear seu futuro profissional. Os resultados dos blocos $B$ e $C$ mostram um cenário preocupante onde a percepção dos alunos é de que na universidade é ensinada e adquirida a parte teórica da formação e se essa está de acordo com as expectativas dos alunos, pode ser avaliada de maneira positiva, pois esse é o papel de uma IES, enquanto que a formação prática precisa ser buscada fora da sala de aula sendo vista como algo à parte. Corroborando essa análise, pode se retomar a afirmação "A formação prática recebida durante o curso é adequada para facilitar a inserção profissional dos alunos" na qual apenas $24 \%$ concordaram com ela enquanto $56 \%$ discordaram. Já que as empresas na hora de contratar valorizam mais um currículo com experiências práticas do que com aprendizagens voltadas para pesquisas, seria esperado que as avaliações das IES tivessem obtido médias mais baixas.

Referente às contribuições da EJ para qualificação e formação profissional dos estudantes de administração, entre os resultados encontrados destaca-se a possibilidade da aprendizagem prática e do desenvolvimento 
de competências por meio dela. A atividade de desenvolver projetos para áreas de atuação voltadas para a Administração como RH, Finanças, Marketing e Gestão, interagindo com clientes que possuem demandas reais para a solução de problemas, gera oportunidades para que os integrantes das EJ se identifiquem com determinada área, auxiliando para a definição de sua trajetória profissional. Também desenvolvem o senso crítico, raciocínio e conhecimento das dinâmicas organizacionais, estimulando a criatividade, pensamento estratégico e outras habilidades desejáveis para um administrador.

No entanto, vale ressaltar que a participação na EJ apenas apresenta a oportunidade de aprendizagem, não significando que ela necessariamente ocorra pelo simples fato de o aluno estar trabalhando nela. $\mathrm{O}$ ambiente de uma EJ é predominado por alunos que recém ingressaram em um contexto universitário, e caso não tenham consciência do papel que precisam exercer e do devido profissionalismo esperado em uma empresa, abre-se espaço para comportamentos que possam prejudicar o desempenho da organização e dos seus processos internos. Posto isto, pela análise dos resultados fica evidenciando o potencial de aprendizagem e complemento à formação que as EJ proporcionam aos seus integrantes, cabendo a eles manterem e tirarem proveito do ambiente no qual estão inseridos para que possam adquirir vantagens competitivas e diferencias que os coloquem à frente dos concorrentes.

\section{Referências}

ALVES, Natália. Inserção Profissional de Jovens. Disponível em http://www.uff.br/ejatrabalhadores/artigo02.htm

BARUCH, Y. Transforming careers: from linear to multidirectional career paths: organizational and individual perspectives. Career Development International, v.9, n. 1, p. 58-73, 2004.

BENNET. Geração Y. Galileu, São Paulo, n. 219, p. 50-53, outubro 2009

BORDIEU, P. La Distincion. Madrid: Taurus, 1988.

BOSLEY, Sara L. C.; ARNOLD, John; COHEN Laurie. How other people shape our careers: A typology drawn from career narratives. Human Relations, v. 62, 2009. Disponível em http://hum.sagepub.com/content/62/10/1487

CARVALHO, M.; STRALIOTTO, S. O não dito sobre os requisitos de seleção de pessoal e as empresas de telefonia móvel: flexibilização, competências e intermediação de empregos na expansão capitalista. Dissertação de mestrado, Porto Alegre - RS, 2011. Disponível em: <http://www.lume.ufrgs.br/bitstream/handle/10183/34154/000791566.pdf?sequence=1>

CERVO, Amado; BERVIAN, Pedro. A. Metodologia científica.4. Ed. São Paulo: Makron Books, 1996.

CHAHAD, José Paulo, Tendências recentes no mercado de trabalho: pesquisa de emprego e desemprego, São Paulo Perspec. vol.17 no.3-4 São Paulo Jul. / Dez. 2003.

CORDEIRO, João Pedro. Modalidades de Inserção Profissional dos Quadros Superiores nas Empresas. Sociologia, problemas e práticas. № 38,2002 , pp. 79-98

COSTA, I. de S. A. da; CAMPOS, A. M. de S. M. Carreira, vivência e construção de si. In: BALASSIANO, M.; COSTA, I. S. A da (Orgs.), Gestão de Carreiras: Dilemas e Perspectivas. Rio de Janeiro: Editora Atlas, 2006, p.65-80 
DOS-SANTOS, M. G.; BRITO-DE-JESUS, K. C.; SOUZA-SILVA, J. C.; SILVA, V. A.; FRANCO, A.P. Como aprendem os empresários juniores no Brasil: Um estudo quantitativo sobre as modalidades de aprendizagem organizacional. EnANPAD, Rio de Janeiro - RJ - 2013. Disponível em: $<$ http://www.anpad.org.br/diversos/trabalhos/EnANPAD/enanpad_2013/04\%20-\%20EOR/PDF\%20EOR\%20\%20Tema\%202/2013 EnANPAD EOR1923.pdf>

FREIRE, P. Pedagogia da Autonomia. São Paulo: Paz e Terra, 1996.

GIL, A.C. Métodos e técnicas de pesquisa social. São Paulo: Atlas, 1999

GUIMARÃES, Nadya Araujo, À procura de trabalho: instituições de mercado e redes, Belo Horizonte, MG, 2009.

GUIMARÃES, Nadya Araujo, A sociologia dos mercados de trabalho, ontem e hoje, CEBRAP no. 85, São Paulo, 2009.

GUIMARÃES, L. G.; SENHORAS, E. M.; TAKEUCHI, K. P. (2003). Empresa Júnior e Incubadora Tecnológica: duas facetas de um novo paradigma de interação empresa-universidade. Anais do Simpósio de Engenharia de Produção, Bauru, 10.

HALL, Douglas. Careers in Organizations. Glenviw, IL. Scott, Foresman, 1976.

HORN, Carlos Henrique. Mercado de Trabalho. In: CATTANI, Antônio David, HOLZMANN, Lorena (org). Dicionário de Trabalho e Tecnologia. Porto Alegre: UFRGS, 2006.

KING, Zella; BURKE, Simon; PEMBERTON, Jim. The 'bounded' career: An empirical study of human capital, career mobility and employment outcomes in a mediated labour market. Human Relations, v. 58, 2005. Disponivel em <http://hum.sagepub.com/content/58/8/981>.

LEMOS, A.H.C., DUBEUX, V. J., PINTO, M.C.S. Empregabilidade dos jovens administradores: uma questão meritocrática ou aristocrática?, Brazilian Business Review, v.8,n.1, p.94-115, 2011

MALHOTRA, N. K. Pesquisa de marketing: uma orientação aplicada. 3. Ed. Porto Alegre: Bookman, 2001

MEZOMO, J.C. Educação qualidade: a escola volta às aulas. São Paulo: J.C. Mezomo, 1994

MIANARDES, Gabriela. Eles ainda têm a força. Você RH, São Paulo, n. 8, p. 22-30, set./Nov. 2009.

MOTTA, F. C. P. A questão da formação do administrador. RAE - Revista de Administração de eEmpresas, FGV, Rio de Janeiro, v. 23, n. 4, out./dez 1983.

NICOLINI, A. Qual será o futuro das fábricas de administradores? In: ENCONTRO NACIONAL DA ASSOCIAÇÃO NACIONAL DOS PROGRAMAS DE PÓS-GRADUAÇÃO EM ADMINISTRAÇÃO, 25., 2003, Campinas. Anais... Campinas : ANPAD, 2003.

NUNES, S.C.; BARBOSA, A.C.Q. A inserção das competências no curso de graduação em Administração: um estudo em universidades brasileiras. XXVII Encontro da Associação Nacional dos Programas de Pós Graduação em administração (ENANPAD, 2003)

PINHEIRO, Beatriz A. de A.; SOUZA, Izabel M. G. de; GONÇALVES, Maria H. B. Formação profissional SENAC: uma proposta para o setor comércioe serviços. Rio de Janeiro: SENAC/DN/DFP, 1996.

POCHMANN, M. A Batalha pelo Primeiro Emprego: As Perspectivas e a Situação Atual do Jovem no Mercado de Trabalho. São Paulo: Publisher Brasil, 2000. v.1. 95 p. 
RAMOS, Cristina; FERREIRA, Jane. Levantamento das Práticas e Conteúdos do Ensino de Empreendedorismo nos Cursos de Graduação em Administração na Cidade de Curitiba - PR. 2004. Disponível em: http://www.anpad.org.br/diversos/trabalhos/EnANPAD/enanpad_2004/ECE/ECE665.pdf.

RODRIGUES, C.; ARRUDA, G.; RIBAS, F.; CATARINA, G.: Relação entre Valores pessoais e Comprometimento Organizacional: $O$ caso das Empresas Juniores de Santa Maria. In:XXXIII Encontro da ANPAD. São Paulo. 2009.

ROCHA DE OLIVEIRA, Sidinei. Estágios para Universitários: representações e implicações na inserção profissional dos jovens brasileiros e franceses. Porto Alegre - RS. 2009. Tese de doutorado. Disponível em: http://www.lume.ufrgs.br/bitstream/handle/10183/18329/000728458.pdf?sequence=1

ROCHA DE OLIVEIRA, Sidinei. Inserção profissional: Perspectivas Teóricas e Agenda de Pesquisa. Revista pensamento contemporâneo em administração (UFF), v.6, p. 124-135, 2012.

ROCHA DE OLIVEIRA, Sidinei; PICCININI, Valmiria Carolina. Mercado de trabalho: múltiplos (des)entendimentos. Revista de Administração Pública (Impresso), v. 45, p. 1517-1538, 2011.

ROCHA DE OLIVEIRA, Sidinei; PICCININI, Valmiria Carolina. Uma análise sobre a inserção profissional de estudantes de administração no Brasil. RAM. Reviste de Administração Mackenzie (Online), v. 12, p. 44-75, 2012.

ROCHA, Márcio. Depois do primeiro choque de realidade. Exame, São Paulo, n. 946, p. 51-54, jul. 2009.

ROCHA, Sonia. A inserção dos jovens no mercado de trabalho. Cadernos CRH. 2008, v.21, n.54, pp. 533550.

ROESCH, Sylvia Maria Azevedo. Projetos de estágio e de pesquisa em administração: guia para estágios, trabalhos de conclusão, dissertações e estudos de caso 3. Ed. São Paulo: Atlas, 2006.

SCHULTZ. Theodore W. O valor econômico da educação. Rio de Janeiro: Zahar, 1967.

SILVA, Mariléia Maria da. Redes de relações sociais e acesso ao emprego entre os jovens: o discurso da meritocracia em questão. Educação e Sociedade.2010, vol.31, n.110, pp. 243-260.

SOUZA, G. C. Empresa Júnior: uma ferramenta facilitadora do processo de aprendizagem através da aplicação imediata de conceitos e teorias à realidade empresarial no ensino de administração no Brasil. Revista ANGRAD, Rio de Janeiro: Associação Nacional dos Cursos de Graduação em Administração, v. 3, n. 4, p. 98-111, out/dez. 2002.

TULGAN, Bruce. Not everyone gets a trophy: how to manage generation Y. San Francisco: Jossey-Bass, 2009.

VASQUEZ, A.; SILVA, F.; NATIVIDADE, J.; RUAS, R.; Aprendizagem em Situações Práticas: A Formação Profissional na Experiência de Alunos em Empresas Juniores no Brasil. In:XXXVI Encontro da ANPAD. Rio de Janeiro. 2012.

WEALE, A. Homo economicus, Homo sociologicus. In S. Hargreaves Heap, M. Hollis, B. Lyons, R. Sugden \& A. Weale (Eds), The theory of choice: A critical guide. Oxford: Blackwell, 1992. 